\title{
KUALITAS PELAYANAN PENDIDIKAN ANAK BINAAN DI LEMBAGA PEMBINAAN KHUSUS ANAK (LPKA) KLAS 1 KUTOARJO KABUPATEN PURWOREJO
}

\author{
Riska Wirawan $^{1}$, Ida Hayu Dwimawanti ${ }^{2}$
}

\begin{abstract}
Analysis of the quality of educational services is very important for progres of educational organization to more improved service. This research aimed to analysis the quality of education equality program paket $C$ in the LPKA Clas 1 Kutoarjo, and for look resistor and support factors in realizing quality educational service of equality program paket $C$ in the LPKA Clas 1 Kutoarjo To obtain an answer from its intended destination, the research approach used is qualitative by using five dimensions of service quality that is tangible, reliability, responsiveness, assurance and empathy, and five factors inhibiting and supporting the quality of service that is a factor of awareness of employees, agencies/organizations, capacity/skills officer, employee interaction, climate and labor relations. The results showed that the quality of education services in equality Packet program $c$ in LPKA Class 1 Kutoarjo is good enough, an outline of some of the dimensions of service quality are met such as educational facilities are available, atmosphere learning cozy, a place of education accessible, employee attitudes is set in the guidelines the treatment of children in LPKA educational requirements and procedures that apply to the conditions, a good employer responses concerned with students, conduct service management system a good education, education fair and non discriminate. Although there are some things that still has shortcomings such as the number of teaching staff, teacher attendance rates and other supporting facilities. Furthermore, to assurance a time education is still not good, the certainty of a teacher who can not be present on schedule, inhibits the teaching and learning activities. So the problem assurance a time education is still needing repair so thah can give quality education service. As for resistor factor od service quality Education LPKA That provision factor Time from Organization And Officers ability factor, Few Obstacles from employe Interaction factor whit Children's. While Namely supports factor Awareness factors apparatus, employee interaction, and climate factors working relationship.
\end{abstract}

Keywords: quality analysis, education service, program packet $C$, children.

\section{PENDAHULUAN}

Pendidikan adalah suatu modal penting dalam hidup manusia apalagi generasi bangsa, dengan pendidikan yang cukup, wawasan, pengetahuan yang luas akan mampu menyiapkan generasi muda yang berkualitas yang mampu membangun bangsa dan

\footnotetext{
${ }^{1}$ Lembaga Swadaya Masyarakat, Pengamat Masalah Publik

${ }^{2}$ Dosen Magister Administrasi Publik, Fakultas IImu Sosial dan Ilmu Politik, Universitas Diponegoro
} 
negara ini menjadi lebih maju. Pasal 31 Ayat 1 UUD 1945 menyatakan Setiap warga negara berhak mendapatkan pendidikan dan Pasal 31 Ayat 2 UUD 1945 yang menyatakan setiap warga negara wajib mengikuti pendidikan dasar dan pemerintah wajib membiayainya, dari pasal 31 ayat 1 dan 2 dapat disimpulkan bahwa seluruh warga negara Indonesia (tanpa terkecuali) berhak mendapatkan pendidikan yang didapat dari negara dan biayanya ditanggung negara.

Pelayanan pendidikan merupakan serangkaian kegiatan atau aktifitas yang dilakukan oleh sekolah atau lembaga lain untuk memberikan pelayanan kepada peserta didik maupun masyarakat sebagai pengguna layanan dalam rangka mengembangkan potensi agar memiliki kecerdasan, pengendalian diri, kepribadian, ahlak mulia, serta ketrampilan yang diperlukan dirinya dan masyarakat (Sukahar, 2014). Layanan pendidikan yang berkualitas merupakan salah satu bentuk kesejahteraan dan penegakan hak asasi manusia. Oleh karena itu harus mendapatkan jaminan dan perlindungan dari negara sebagai penyelenggara layanan.

Pada kenyataannya masih banyak permasalahan yang ditemukan dalam penyelenggaraan layanan pendidikan di Indonesia, seperti kurangnya tenaga pendidik, kurangnya penggalian potensi peserta didik, masih tingginya biaya untuk mendapatkan pendidikan, banyaknya anak yang putus sekolah, tidak adanya jaminan pendidikan ketika mereka menyelesaikan pendidikannya, sampai sarana prasarana/fasilitas yang belum layak dan tidak merata. Saat ini masih banyak anak-anak yang membutuhkan layanan pendidikan tetapi tidak dapat menempuh pendidikan formal dengan berbagai alasan, di antaranya anak-anak yang sedang bermasalah dengan hukum di Lembaga Pembinaan Khusus anak (LPKA) klas 1 Kutoarjo. LPKA sendiri mempunyai dua jenis pelayanan, yaitu pelayanan pembinaan yang meliputi seluruh kegiatan kepribadian dan kemandirian dan pelayanan pendidikan meliputi kegiatan pendidikan nonformal kejar paket.

Diharapkan LPKA Klas 1 Kutoarjo dalam memberikan layanan pendidikan kepada anak dapat memberikan layanan pendidikan yang berkualitas seperti sarana prasarana pendidikan yang memadai, jumlah tenaga pendidik yang cukup sesuai dengan kualifikasi pendidikannya, dan kepastian jadwal pelayanan pendidikan. Diharapkan mereka akan mendapat hak yang sama seperti anak-anak yang menempuh pendidikan 
formal karena dengan proses pendidikan yang berkualitas tentu akan membentuk sumber daya yang mandiri kreatif, dan mampu bersaing di kehidupan yang baru setelah mereka keluar dari LPKA.

Namun kenyataan yang ada menunjukkan bahwa sarana prasarana pelayanan pendidikannya masih kurang mendukung untuk proses belajar anak. Kondisi ruang kelas yang minim atau seadanya juga membuat proses pendidikan menjadi kurang nyaman. Kurangnya tenaga pendidik menjadi salah satu permasalahan yang dihadapi LPKA dalam mewujudkan pelayanan pendidikan yang berkualitas. Ketidakpastian jadwal pendidikan dan masih rendahnya tingkat kehadiran pengajar juga menjadi masalah. Keterbatasan anggaran atau minimnya dana operasional untuk pelayanan pendidikan nonformal membuat pelayanan pendidikan dirasa kurang maksimal.

Lembaga Pembinaan Khusus Anak Klas 1 Kutoarjo Kabupaten Purworejo adalah satu-satunya lembaga pembinaan khusus bagi anak di daerah Jawa Tengah dan DIY, yang menampung anak didik termasuk anak pidana. Disamping itu di Lembaga Pembinaan Khusus Anak Klas 1 Kutoarjo dilaksanakan kegiatan pelayanan pendidikan terhadap anak binaan/narapidana. Bentuknya adalah melaksanakan kegiatan pendidikan nonformal berupa pendidikan kesetaraan kejar paket untuk anak didik.

\section{METODE PENELITIAN}

Penelitian ini menggunakan pendekatan deskriptif kualitatif. Teknik pengumpulan data dilakukan dengan metode wawancara, observasi, dan dokumentasi. Lokasi penelitian bertempat di LPKA Klas 1 Kutoarjo Kabupaten Purworejo.

Fokus penelitian ini adalah menganalisis kualitas layanan pendidikan pada program kesetaran kejar paket $\mathrm{C}$ yang ada di LPKA Klas 1. Program tersebut menjadi program kesetaraan paling tinggi setingkat sekolah menengah atas/SMA dan memiliki peserta didik yang paling banyak di antara lainnya. Selain itu juga menganalisis faktorfaktor penghambat dan pendukung dalam mewujudkan kualitas pelayanan pendidikan pada program kesetaran kejar paket C di LPKA. Fenomena penelitian mencakup dimensi kualitas dari Zeithaml, Berry dan Parasuraman (dalam Hardiyansyah, 2011), yaitu meliputi tangible (bukti langsung), reliability (kehandalan), responsiveness (daya tanggap), assurance (jaminan), dan emphaty (kepedulian). Juga faktor-faktor yang mempengaruhi kualitas dari Moenir (1992) dan Atep Adya Barata (2004) faktor 
kesadaran aparat yang terlibat dalam kegiatan pelayanan, faktor organisasi yang merupakan alat serta pelaku mekanisme kegiatan pelayanan, kemampuan/ketrampilan petugas, interaksi jajaran pegawai organisasi/perusahaan, iklim kerja dan keselarasan hubungan kerja

Teknik analisis data dilakukan melalui tiga tahap, antara lain pemilihan data (reduksi data), penyajian data (data display), penarikan kesimpulan (drawing conclusion), dan verifikasi data (data verification).

\section{HASIL DAN PEMBAHASAN}

\section{Kualitas Layanan Pendidikan LPKA}

\section{Tangible (Berwujud)}

Tangible berupa sarana dan prasarana atau fasilitas fisik yang ada di Lembaga Pembinaan Khusus Anak Klas 1 Kutoarjo. Sudah tersedia ruang kelas untuk layanan pendidikan program kejar paket $\mathrm{C}$ meskipun masih ada kekurangan beberapa sarana prasarana yang lainnya, yaitu pada buku-buku materi atau modul-modul pembelajaran dan ruang kelasnya bergantian dengan program kejar paket yang lainnya.

Kemudahan akses sudah baik ditandai dengan adanya Pusat Kegiatan Belajar Masyarakat (PKBM) untuk mempermudah layanan pendidikan anak binaan khususnya program kejar paket $\mathrm{C}$ di mana ruang kelasnya mudah dijangkau. Suasana tempat belajar bersih, tertata, lingkungan cukup nyaman untuk kegiatan belajar. Secara keseluruhan dimensi tangible (bukti langsung) ini sudah baik meski masih ada beberapa yang perlu diperbaiki, guna memberikan pelayanan pendidikan kejar paket $\mathrm{C}$ yang berkualitas di LPKA Klas 1 Kutoarjo.

\section{Reliability (Kehandalan)}

Reliability atau kehandalan Lembaga Pembinaan Khusus Anak Klas 1 Kutoarjo dapat dilihat dari sikap pegawai dalam memberikan layanan pendidikan secara cermat, handal, dan memberi kemudahan prosedur. LPKA Klas 1 Klas 1 Kutoarjo memberikan layanan semaksimal mungkin, petugas layanan pendidikan telah berusaha memberikan pelayanan dengan cermat. Pegawai tetap LPKA juga ada yang merangkap menjadi pengajar Kejar Paket C sehingga harus mendatangkan pengajar dari luar. Lembaga Pembinaan Khusus Anak Klas 1 Kutoarjo harus memperhatikan ketersediaan tenaga 
pengajar supaya peningkatan layanan pendidikan terutama program Kejar Paket C dapat terlaksana dengan baik. Untuk prosedur dan syarat pelayanan sudah cukup jelas.

Dimensi reliability (kehandalan) petugas layanan pendidikan telah berusaha memberikan pelayanan dengan maksimal, tetapi masih kurang dan perlu ada hal yang ditambah, seperti jumlah pegawai atau tenaga pendidik program kejar paket C di LPKA yang sesuai dengan latar belakang pendidikan, sedangkan untuk prosedur dan syarat pelayanan sudah cukup jelas.

\section{Responsivenes (Ketanggapan)}

Responsiveness merupakan dimensi ukuran kualitas layanan publik tentang kesediaan petugas untuk membantu pengguna layanan dan kesanggupan untuk membantu menyediakan pelayanan secara cepat dan tepat.

Responsiveness atau daya tanggap pegawai di layanan pendidikan LPKA terlihat pada sikap perilaku dan daya tanggap petugas LPKA dalam layanan pendidikan yang dilandaskan pada Asas Peradilan anak. Pegawai memberi respon positif kepada anak didik meskipun masih ada pengajar yang terkadang tidak hadir untuk memberi pendidikan pada anak binaan Kejar Paket C di LPKA.

Berdasarkan analisis hasil penelitian mengenai dimensi responsiveness (ketanggapan petugas), layanan pendidikan LPKA Klas 1 Kutoarjo memiliki responsivitas baik karena telah mengacu pada asas-asas yang wajib dilakukan petugas meskipun masih terdapat kekurangan pada tingkat kehadiran pengajar yang dapat mengganggu proses pendidikan kejar paket C di LPKA.

\section{Assurance (Jaminan)}

Jaminan kepastian waktu pendidikan di LPKA belum sesuai dengan jadwal yang telah ditentukan sehingga jam pelajaran anak menjadi tidak teratur. Untuk kepastian biaya dalam layanan pendidikan sudah baik, anak-anak mendapatkan jaminan biaya pendidikan secara gratis sehingga tidak perlu memikirkan masalah biaya. Mengenai biaya pelayanan pendidikan di LPKA Klas 1 Kutoarjo mendapat biaya dari Pemerintah melalui Dinas Pendidikan Kabupaten yang kemudian dibagi-bagi ke setiap PKBM yang ada dengan jumlah yang berbeda-beda. Untuk biaya pendidikan program Kejar Paket C anak di LPKA klas 1 Kutoarjo sudah gratis, tanpa ada biaya pendaftaran. Dalam hal jaminan sikap pegawai maupun pengajar mereka ramah dan sopan. 
Mengenai assurance (jaminan) Lembaga Pembinaan Khusus Anak Klas 1 Kutoarjo dapat dikatakan masih kurang meskipun sudah memiliki atau tersedia jadwal mata pelajaran dan jadwal pengajar program Kejar Paket C, tetapi pada permasalahan waktu layanan pendidikan di LPKA, terutama kepastian waktu pengajar hadir belum bisa sesuai jadwal. Oleh karena itu masalah kepastian waktu masih memerlukan perbaikan supaya dapat memberi pelayanan yang berkualitas secara cepat dan tepat kepada anak binaan. Untuk kepastian biaya layanan sudah baik, anak-anak dan orang tua tidak lagi dibebani biaya tambahan untuk pendidikan.

\section{Emphaty (Empati)}

Lembaga Pembinaan Khusus Anak Klas 1 Kutoarjo mempunyai tugas menampung, merawat dan membina serta menyelenggarakan layanan pendidikan bagi anak binaan sehingga pegawai dituntut untuk memberikan pelayanan yang berkualitas, salah satunya dengan rasa empati kepada anak binaan dalam pendidikan Kejar Paket $\mathrm{C}$ di LPKA Klas 1 Kutoarjo. LPKA selalu mengutamakan kepentingan anak termasuk di dalamnya layanan pendidikan, seperti penyediaan peralatan belajar dan pengelolaan layanan pendidikan yang baik meliputi perencanaan, evaluasi hingga penilaian.

Layanan pendidikan Kejar Paket C di LPKA dilakukan secara adil dan tidak membeda-bedakan anak binaan. Semua memperoleh pendidikan, hanya saja ada perbedaan dalam hal materi pendidikan sesuai tingkatan yang mereka ikuti. Empati pelayanan pendidikan di LPKA Klas 1 Kutoarjo sudah baik dilihat dari prioritas pegawai dalam pendidikan, sikap, perhatian dan keadilan yang diberikan oleh pegawai/petugas dalam melayani kebutuhan pendidikan anak.

\section{Faktor-faktor Penghambat dan Pendukung Kualitas Layanan Pendidikan di LPKA}

\section{Faktor Kesadaran Aparat}

Salah satu dimensi yang mempengaruhi kualitas layanan pendidikan adalah faktor kesadaran aparat, meliputi komitmen, tanggung jawab dan motivasi. Terkadang permasalahan yang sering muncul adalah pegawai pelayanan sering lupa dengan tugas pokok dan tanggung jawab yang harus mereka kerjakan, yang ahirnya menjadi permasalahan dan penghambat ketika memberikan layanan pendidikan paket $\mathrm{C}$ bagi anak binaan di LPKA klas 1 Kutoarjo. Namun apabila pegawai bekerja sepenuh hati 
sesuai dengan komitmen dan tanggungjawabnya maka akan menjadi faktor pendukung yang akan mnghasilkan pelayanan pendidikan yang berkualitas.

Lembaga Pembinaan Khusus Anak Klas 1 Kutoarjo memiliki faktor kesadaran aparat dalam kualitas layanannya. Berdasarkan hasil penelitian faktor kesadaran aparat di LPKA Klas 1 Kutoarjo dalam layanan pendidikan anak terlihat dari komitmen, tanggung jawab dan motivasi dari pegawai yang ada. Semua pegawai berusaha melaksanakan pekerjaanya sesuai tugas pokok dan fungsinya masing-masing. Untuk menjaga komitmen dan rasa tanggung jawab, pegawai LPKA dalam memberikan layanan pendidikan di LPKA membuat visi misi dalam layanan pendidikan.

\section{Faktor Lembaga/Instansi}

Faktor lembaga adalah salah satu faktor penting terhadap keberhasilan pelayanan yang dilakukan. Apabila sistem lembaga tidak berjalan dengan baik maka kualitas yang dihasilkan akan buruk, begitu juga sebaliknya jika lembaga/instansi dapat mengarahkan dan mengelola sistem kepegawaian maka kualitas layanan akan baik pula.

LPKA Klas 1 Kutoarjo sebagai lembaga yang menyelenggarakan layanan pendidikan program Kejar Paket $\mathrm{C}$ telah mengelola layanan pendidikan dengan membuat perencanaan hingga evaluasi yang mengacu pada aturan perundang undangan. Waktu pendidikan juga sudah jelas, kurikulum hampir sama dengan sekolah formal, yaitu Kurikulum Tingkat Satuan Pendidikan (KTSP) yang dalam pelaksanaanya disesuaikan dengan kondisi dan situasi anak binaan. Namun selain itu masih mengalami hambatan dengan keterbatasan waktu pendidikan yang hanya 45 menit.

Faktor lembaga sebagai pelaku kegiatan layanan pendidikan di LPKA Kutoarjo dapat simpulkan bahwa lembaga telah mengelola layanan pendidikan dengan baik. Sudah ada perencanaan hingga evaluasi dalam pendidikan Kejar Paket C serta aturan UU Nomor 20 Tahun 2003 tentang sistem pendidikan nasional meskipun masih ada sedikit hambatan keterbatasan waktu pendidikan.

\section{Faktor Kemampuan Petugas}

Salah satu dimensi yang mempengaruhi layanan pendidikan adalah faktor kemampuan atau ketrampilan petugas, meliputi kecakapan/pengetahuan pegawai dan tingkat pendidikan pegawai. Hal itu sangat diperlukan sebagai modal dalam layanan terutama pendidikan. Apabila mendapatkan sumberdaya manusia yang sesuai, tepat dan 
berkualitas maka akan menjadi faktor pendukung untuk menghasilkan pekerjaan yang berkualitas pula. Sama halnya di Lembaga Pembinaan Khusus Anak Klas 1 Kutoarjo dalam layanan pendidikan Kejar Paket C. Ketrampilan pegawai dalam hal layanan pendidikan sudah mampu dalam penguasaan dan penyampaian materi pelajaran, meskipun masih terdapat sedikit permasalahan di mana tingkat pendidikan pengajar belum seluruhnya setara, status pegawai yang tidak tetap dan hanya mengabdi sebagai pengajar di LPKA.

\section{Faktor Interaksi Pegawai}

Hubungan yang terjalin antara pegawai layanan pendidikan Kejar Paket C di LPKA dengan anak binaan terjalin dengan baik. Dalam setiap kegiatan pendidikan juga selalu dikomunikasikan dengan anak binaan. Ini terlihat juga LPKA sebagai lembaga penyelenggara dan PKBM sebagai pelaksanan layanan pendidikan kegiatan Kejar Paket C di LPKA telah melaksanakan tugasnya, memberikan informasi kepada anak binaan mengenai pembelajaran yang berlaku di dalam LPKA ini.

Dalam hal interaksi pegawai di LPKA telah terjalin kerjasama yang baik antara teman kerja. Tingkat kepercayan sesama teman kerja begitu terjalin dengan baik meskipun masih ada sedikit interaksi yang kurang maksimal dengan anak ketika proses belajar mengajar karena anak malas dan sulit diatur. Namun pegawai saling mendukung sehingga apabila teman kerja sedang mengalami kesulitan dalam menyelesaikan pekerjaan mereka saling membantu satu sama lain.

\section{Faktor Iklim Hubungan Kerja}

Faktor iklim dan hubungan kerja ini sangat berdampak pada kualitas layanan pendidikan program Kejar Paket C LPKA. Untuk hubungan antar pegawai terjalin dengan harmonis, kerja sama baik pimpinan dan bawahan terjalin dengan lancar.

Jika tanpa ada kerjasama dalam layanan pendidikan di LPKA maka tujuan dan sasaran akan sulit tercapai. Perubahan kepemimpinan berdampak pada hubungan keharmonisan kerja lembaga, apabila kepemimpinan berubah, otomatis gaya kepemimpinan juga berubah. Dalam hal iklim kerja dengan lembaga lainnya, telah terjalin dengan baik mereka saling mendukung dalam setiap kegiatan dan perkembangan pendidikan anak di LPKA Klas 1 Kutoarjo. 


\section{PENUTUP}

\section{Kesimpulan}

Sesuai analisis hasil penelitian dan pembahasan penelitian, maka dapat ditarik kesimpulan bahwa kualitas layanan pendidikan anak binaan di Lembaga Pembinaan Khusus Anak Klas 1 Kutoarjo yaitu sebagai berikut :

1. Kualitas LayananPendidikan Anak LPKA

Kualitas layanan pendidikan dalam program kesetaraan Kejar Paket C di LPKA Klas 1 Kutoarjo sudah cukup baik. Kelima dimensi kualitas pelayanan sudah terpenuhi meskipun beberapa indikator dari lima dimensi tersebut masih memiliki kekurangan pada tangible, responsiveness, dan assurance. Pada dimensi tangible masih ada kekurangan dalam beberapa sarana prasarana pendukung, yaitu kekurangan buku-buku materi atau modul-modul pembelajaran. Pada dimensi responsiveness masih terdapat kendala pada tingkat kehadiran pengajar. Selanjutnya dalam hal dimensi assurance dilayanan pendidikan Kejar Paket C LPKA, kepastian waktu kehadiran pengajar belum bisa sesuai jadwal sehingga menghambat kegiatan belajar mengajar. Oleh karena itu masalah kepastian waktu masih memerlukan perbaikan supaya dapat memberi pelayanan pendidikan yang berkualitas kepada anak binaan. Terlepas dari kekurangan-kekurangan pada dimensi di atas semuanya sudah dilakukan dengan usaha semaksimal mungkin, seperti suasana tempat belajar yang nyaman, tempat pendidikan mudah diakses, perlakuan petugas diatur sesuai Pedoman Perlakuan anak di LPKA, syarat dan prosedur pendidikan diterapkan sesuai ketentuan. Dimensi yang paling baik adalah emphaty karena dari kedua indikatornya, prioritas pegawai dalam pendidikan anak sudah baik dan keadilan pendidikan sudah terwujud dengan tidak diskriminatif.

2. Faktor Penghambat Kualitas Layanan pendidikan LPKA

Terdapat beberapa faktor yang menghambat LPKA dalam mewujudkan layanan pendidikan kesetaraan Kejar Paket $\mathrm{C}$ yang berkualitas, yaitu dari faktor lembaga ada keterbatasan dalam penyediaan waktu pendidikan yang hanya 45 menit untuk setiap mata pelajaran sehingga kurang maksimal untuk menyampaikan materi setiap mata pelajaran. Selanjutnya dari faktor kemampuan petugas, tingkat 
pendidikan pengajar belum seluruhnya setara, pengajar Kejar Paket C juga berstatus tidak tetap. Dari faktor interaksi pegawai dengan anak dalam kegiatan pendidikan di kelas masih belum maksimal.

3. Faktor Pendukung Kualitas Layanan pendidikan LPKA

Beberapa faktor pendukung dalam mewujudkan layanan pendidikan Kejar Paket C yang berkualitas di LPKA Klas 1 Kutoarjo antara lain faktor kesadaran aparat dengan adanya komitmen, tanggung jawab, dan motivasi cukup baik dalam pendidikan, terlihat dari usaha mendidik dengan iklas dan perhatian. Selanjutnya pada faktor lembaga/instansi, dalam hal pengelolaan pendidikan dilakukan dengan baik melalui perencanaan, pelaksanaan, evaluasi dan penilaian. Hubungan interakasi dan komunikasi pegawai terjalin harmonis, saling bekerja sama sehingga memperlancar proses layanan pendidikan Kejar Paket C bagi anak. Faktor pendukung lainnya, yaitu faktor iklim dan hubungan kerja di mana adanya kerja sama dengan lembaga-lembaga lain dapat terjalin dengan baik untuk meningkatkan kualitas layanan pendidikan.

\section{Saran}

1. Menambah waktu atau jam pelajaran untuk pendidikan anak binaan Kejar Paket C, dapat dibuat seperti sekolah formal 2 x 45 menit per mata pelajaran agar lebih efektif.

2. Menambah waktu pendidikan menjadi 6 hari, di luar jadwal yang telah ditentukan seperti memanfaatkan hari Jumat atau Minggu.

3. Mengikutsertakan pengajar Kejar Paket $\mathrm{C}$ pada diklat-diklat atau seminar tentang pendidikan nonformal.

4. Memberi sanksi kepada pengajar yang tidak hadir di LPKA berupa potong honor/gaji agar kedisiplinan dan kepastian waktu pendidikan dapat terlaksana dengan baik.

5. LPKA dapat bekerjasama dengan melibatkan orang tua anak dalam mengontrol pendidikan setiap periode tertentu. 


\section{DAFTAR PUSTAKA}

Alifuddin, Moh. 2011. Kebijakan Pendidikan Nonformal (Teori, Aplikasi dan Implikasi). Jakarta: MAGNA Script Publishing.

Barata, Atep Adya. 2004. Dasar-Dasar Pelayanan Prima. Jakarta: PT Gramedia Pustaka Utama.

Bungin, M. Burhan. 2010. Penelitian Kualitatif Komunikasi, Ekonomi, Kebijakan Publik, dan Ilmu Sosial lainnya. Jakarta: Kencana.

Departemen Pendidikan Nasional. 2008. Kamus Besar Bahasa Indonesia Pusat Bahasa Edisi Keempat. Jakarta: PT gramedia Pustaka Umum.

Dwiyanto, Agus. 2008. Mewujudkan Governance Melalui Pelayanan Publik. Yogyakarta: Gadjah Mada University Press.

Endar, Sugiarto. 1999. Psikologi Pelayanan Dalam Industri Jasa. Jakarta: Gramedia Pustaka Utama.

Hardiansyah. 2011. Kualitas Pelayanan Publik (Konsep, Dimensi dan Implementasinya). Yogyakarta: Gava Media.

Ikke, Dewi Sartika. 2002. Quality Service in Education. Edisi Khusus Untuk Kalangan Mahasiswa. Bandung: Yayasan Potensia.

Indiahono, Dwiyanto. 2009. Perbandingan Administrasi Publik Model, Konsep dan Aplikasi. Yogyakarta: Gava Media.

Komar, Oong. 2006. Filsafat Pendidikan Nonformal. Bandung: Pustaka Setia.

Made, Ansar dkk. 2015. Innovation Of Public Service In Meeting The Basic Needs In Gorontalo, Indonesia. International Journal of Academi Research, Vol 7, No 1, January, 2015 Doctor Candidate In Public Administration Satate university Of Makasar, Professor Of Public Administration, Universitas Negeri Makasar, Professor Of Mathematics, Universitas Negeri Makasar ( IND).

Marzuki, Saleh. 2010. Pendidikan Nonformal (Dimensi Dalam Keaksaraan Fungsional, Pelatihan dan Andragogi). Malang: Remaja Rosdakarya.

Moenir, H.A.S, 2002. Manajemen Pelayanan Umum di Indonesia. Jakarta: Bumi Aksara.

Moleong, Lexy J. 2010. Metodelogi Penelitian Kualitatif. Bandung: Remaja Rosdakarya.

Mufiz, Ali. 2004. Pengantar Administrasi Negara. Jakarta: Pusat Penerbit Universitas Terbuka.

Nanang, Fattah. 2004. Landasan Manajemen pendidikan. Bandung: Remaja Rosda Karya.

O. Adetunji, V.S.S. Yadavalli, A. Malada. 2013. Assement Of The Quality Of Service Provided By A National Regulatory Institution. South African Journal of Industrial EngineringMay 2013 May Vol 24 (1) Department of industrial and System Engineering University of Pretoria, South Africa. 
Permadi, Leo. 2013. Implementasi Program Pendidikan Nonformal di Lembaga Pemasyarakatan Anak Kelas II A Kutoarjo. Fakultas Ilmu Sosial UNY.

Pustikaningsih, Adeng dkk. 2013. Analisis Kualitas Pelayanan Terhadap Kepuasan Mahasiswa Fakultas Ekonomi Universitas Negeri Yogyakarta. Jurnal Nominal Vol. 2 No. 1, Fakultas Ekonomi Universitas Negeri Yogyakarta.

Septiani, Eka. 2013. Pembinaan Anak Didik pemasyarakatan melalui Pendidikan Kesetaraan kejar Paket A, B, dan Paket C di Lembaga pemasyarakatan Anak Kutoarjo. Universitas Negeri Semarang.

Setioko, Aji. 2012. Peningkatan Mutu Pelayanan Pendidikan di MI Lukman Al Hakim Slawi Kabupaten Tegal. Jurnal Pendidikan Ekonomi, Vol. 1, No. 1, Prodi Pendidikan Ekonomi, Program Pascasarjana, Universitas negeri Semarang.

Sianipar. 1998. Pelayanan Prima. Jakarta: LAN.

Sinambela, Lijan Poltak. 2006. Reformasi Pelayanan Publik Teori, Kebijakan, Implementasi. Jakarta: Bumi Aksara.

Siswoyo, Dwi., dkk. 2007. Ilmu Pendidikan. Yogyakarta: UNY PRES.

Sugiyono. 2011. Metode Penelitian Pendekatan Kuantitatif, Kualitatif R\&D. Bandung: Alfabeta.

Sukahar. 2014. Analisis Kualitas Pelayanan Pendidikan di Sekolah Menegah Pertama Negeri 5 Demak. Semarang: Universitas Diponegoro.

Suwitri, Sri. 2011. Konsep Dasar Kebijakan Publik. Semarang: Penerbit Undip.

Syafiie, Inu Kencana. 2014. Sistem Administrasi Negara. Jakarta: PT Bumi Aksara.

Syukri, Agus Fanar. 2010. Standar Pelayanan Publik Pemda. Banten: Indonesia Quality Research Agency (IQRA).

Tangkilisan, Hessel Nogi S. 2007. Manajemen Publik. Jakarta: PT Grasindo.

Wibisono, Sandi. 2016. Pembinaan Terhadap Anak Didik Pemasyarakatan di Lembaga Pembinaan Khusus Anak. Fakultas Hukum. Universitas Muhamadiyah Surakarta.

Winarsih, Atik Septi., dan Ratmiko. 2010. Manajemen Pelayanan. Penerbit Pustaka Pelajar, Yogyakarta.

Yamit, Zulian. 2001. Manajemen Kualitas Produkdan Jasa. Yogyakarta: Penerbit Enkonisia.

Peraturan Pemerintah Nomor 73 Tahun 1991 Tentang Pendidikan Luar Sekolah.

Peraturan Menteri Pendidikan Nasional Republik Indonesia Nomor 49 Tahun 2007 Tentang Standar Pengelolaan Pendidikan oleh Satuan Pendidikan Nasional.

Rencana Strategis Departemen Pendidikan Nasional 2005-2009.

Undang-Undang Nomor 20 Tahun 2003 Tentang Sistem Pendidikan Nasional.

Undang Undang Perlindungan Anak No 23 Tahun 2002.

www.scribd.com/mobile/doc/252006430/Profile-Correctional-Institution-forJuvenile Class-IIA-Kutoarjo 